\title{
Alkali-Decomposition of Poly(ethylene terephthalate) in Mixed Media of Nonaqueous Alcohol and Ether. Study on Recycling of Poly(ethylene terephthalate)
}

\author{
Lian-Chun Hu, ${ }^{*}$ Akira OKu, ${ }^{*, * * \dagger}$ Etsu Yamada, ${ }^{* * *}$ and Kohei Tomari** \\ ${ }^{*}$ Center for Environmental Science, Kyoto Institute of Technology, Matsugasaki, Sakyo-ku, Kyoto 606, Japan \\ ** Department of Chemistry and Materials Technology, \\ Kyoto Institute of Technology, Matsugasaki, Sakyo-ku, Kyoto 606, Japan
}

(Received November 27, 1996)

\begin{abstract}
Alkali-decomposition (depolymerization) of poly(ethylene terephthalate) (PET) was studied in a mixed solvent of an alcohol (ethanol or methanol) and ether (dioxane, tetrahydrofuran, or dimethoxyethane). The time for complete decomposition (>96\%) of solid PET with $\mathrm{NaOH}$ in methanol at $60^{\circ} \mathrm{C}$ was $40 \mathrm{~min}$ when dioxane $(10 \mathrm{vol} \%)$ was added as co-solvent in the reaction mixture, whereas $7 \mathrm{~h}$ without dioxane. Disodium terephthalate, a product, precipitated quantitatively in the media and was separated easily. From the filtrate, ethylene glycol (EG) was recovered by distillation while, for practical use, the major portion of the filtrate was recycled repeatedly as the reaction medium.

KEY WORDS Poly(ethylene terephthalate) (PET) / Plastic Recycling / Alkali Decomposition / Mixed Solvent System / Methanol / Ethanol / Dioxane / Terephthalic Acid /
\end{abstract}

For recycling poly(ethylene terephthalate) (PET) as terephthalic acid (TPA) and ethylene glycol (EG), there have been reported a number of decomposition or depolymerization methods. These methods involve (1) hydrolysis with acids or bases in aqueous media ${ }^{1-3}$; (2) alcoholysis or glycolysis by catalytic reactions ${ }^{4-11}$; or (3) non-catalytic hydrolysis or alcoholysis in super critical media. ${ }^{12-18}$ To deal with recovered PET plastics with different shapes, colors, plastic composites, chemical additives, and impurities, several different methods are necessary for solving the waste plastic problem. However, the methods hitherto reported generally require severe conditions such as strong acids or bases, high temperatures and pressures, longer reaction times and tedious product separation.

We recently reported the alkali-decomposition of PET in nonaqueous EG, where disodium salt of TPA and EG were reproduced quantitatively under mild treatment conditions. ${ }^{19}$ With this method, the chemicals to be consumed are sodium hydroxide $(\mathrm{NaOH})$ and mineral acids such as hydrochloric acid $(\mathrm{HCl})$ and sulfuric acid $\left(\mathrm{H}_{2} \mathrm{SO}_{4}\right)$. Moreover, the waste to be emitted on theoretical basis is only sodium sulfate or chloride, which can be reused on commercial bases. ${ }^{20}$ While the use of nonaqueous EG as the solvent is the key of our method, relatively high temperatures $160-180^{\circ} \mathrm{C}$ are required for practical purposes. In parallel with our study, alkalidecomposition of PET in a mixed medium of an alcohol and aprotic solvent such as dimethyl sulfoxide (DMSO), $N, N$-dimethylformamide (DMF) and $N$-methyl-2-pyrrolidone (NMP) was reported. ${ }^{21}$ However, the method seems impractical because the separation of EG from these high-boiling media must be tough and, moreover, the solvents are not stable enough under the required severe treatment conditions. ${ }^{22}$

To lower the treatment temperatures in ordinary solvents which are thermally and chemically stable, we adopted mixtures of low boiling alcohols and ethereal

\footnotetext{
† To whom the correspondence must be addressed.
}

additives such as dioxane (DX), tetrahydrofuran (THF), or 1,2-dimethoxyethane (DME). In general, the rate of alkali-decomposition of PET depends markedly on the activity of hydroxide ion $\mathrm{HO}^{-}$, which is strengthened in the presence of cation-inclusion compounds such as crown ethers in aprotic solvents. ${ }^{23}$ However, the chemicals are too expensive to be used for practical processes such as plastic recycling. In this regard, we adopted inexpensive ethereal additives such as DX, THF, and DME in combination with ethanol (EtOH) and methanol $(\mathrm{MeOH})$ in expectation of rate-enhancement effects to lower the treatment temperatures.

The objective of the present study was to develop an improved method of alkali-decomposition (depolymerization) of PET more or less comparable to our reported method with $\mathrm{EG}^{19}$ and beneficial to solving the social problem of plastic recycling. This report presents the results of nonaqueous alkali-decomposition of PET in alcohol-ethereal additive media at the temperatures lower than $80^{\circ} \mathrm{C}$. Almost quantitative yields of disodium or dipotassium terephthalate (TPA- $\mathrm{Na}_{2}$ or $-\mathrm{K}_{2}$ ) and EG are attained within a period from $15 \mathrm{~min}$ to $1 \mathrm{~h}$. In this method, preliminary dissolution of PET is not necessary because TPA-salts are formed on the surface of solid PET and precipitated quantitatively. ${ }^{24}$ EG remains in the medium and is recycled as a part of the solvent system, while increased EG must be continuously distilled to obtain EG.

\section{EXPERIMENTAL}

\section{Materials and Reagents}

We used two pure PET pellets $2 \mathrm{~mm}$ length $\times 1 \mathrm{~mm}$ diameter with $M_{w}=30000$ (Type-1) and 33000 (Type2). ${ }^{25}$ In addition, cut-pieces $(3 \times 3 \times 0.5 \mathrm{~mm})$ of PET bottles were used after washing and drying. Commercially available reagent-grade $\mathrm{MeOH}, \mathrm{EtOH}, \mathrm{DX}, \mathrm{THF}$, DME, $\mathrm{NaOH}$, and $\mathrm{KOH}$ (pellets with $>96$ and $80 \%$ purity determined by titration, respectively) were used without purification. For titration of $\mathrm{NaOH}$ and $\mathrm{KOH}$, 


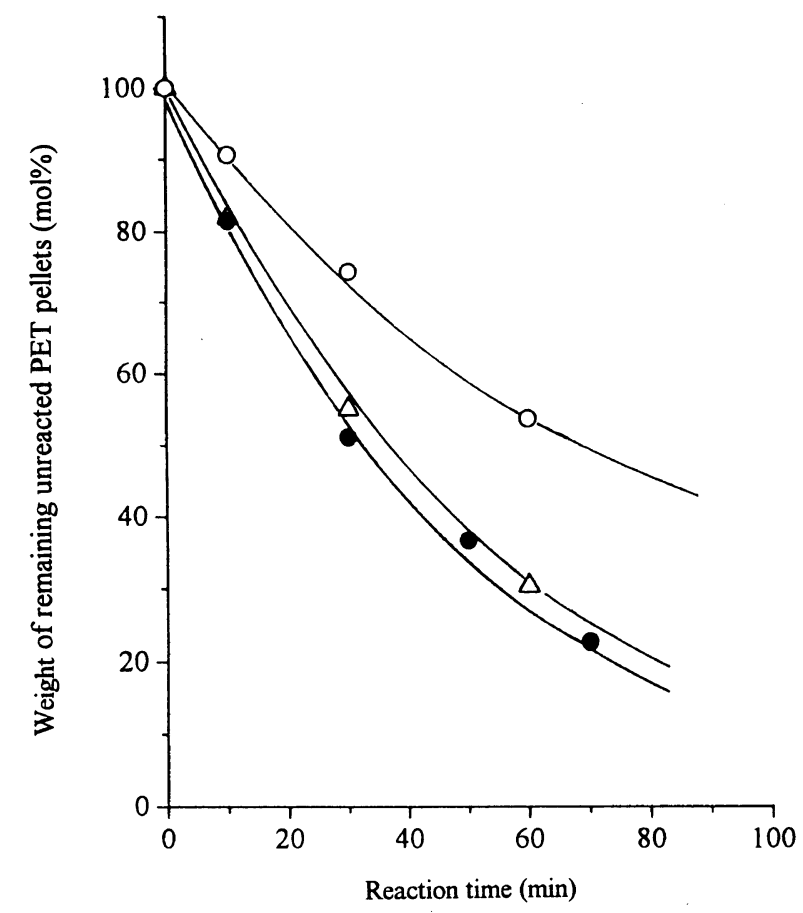

Figure 1. Effects of alcohol on alkali-decomposition of PET pellets with $\mathrm{KOH}$ at $60^{\circ} \mathrm{C}$ : in methanol $(\triangle)$, ethanol $(\bigcirc)$, and 1-propanol $(\bigcirc)$.

commercially available $1 \mathrm{~N}-\mathrm{HCl}$ solution was used after dilution to $0.2 \mathrm{~N}$. 1,3-Dimethyl-2-imidazolidinone (DMI), also used as a solvent of the decomposition, was available from Mitsui Chemical Co. ${ }^{26}$

\section{General Procedure of the Nonaqueous Alkali-Decomposi- tion}

Pellets of $\mathrm{NaOH}(0.41 \mathrm{~g}, 0.01 \mathrm{~mol})$ or $\mathrm{KOH}(0.69 \mathrm{~g}$, $0.01 \mathrm{~mol}$ ) were dissolved in $4 \mathrm{ml} \mathrm{MeOH}$ or $\mathrm{EtOH}$, respectively, in which $1 \mathrm{ml}$ ethereal additive was added. To this alkali hydroxide solution were added PET pellets $(0.96 \mathrm{~g}, 5 \mathrm{mmol}$ on the basis of the repeating unit of monomers) and PET was decomposed under stirring for a specified period at a specified temperature in this solid/liquid reaction system. The reaction mixture was cooled rapidly by immersing the flask in ice water, and quenched by pouring into $50 \mathrm{ml}$ distilled water. The remaining $\mathrm{NaOH}$ or $\mathrm{KOH}$ was titrated by $0.2 \mathrm{~N}-\mathrm{HCl}$ solution to $\mathrm{pH}=7$ to determine the consumed amount of $\mathrm{NaOH}$ or $\mathrm{KOH}$ which is equivalent to the amount of TPA- $\mathrm{Na}_{2}$ or TPA-K 2 .

After the titration, the mixture was filtered to remove undecomposed PET solids, and weight was measured. The filtrate was acidified by excess $\mathrm{HCl}$ to crystallize TPA out of the aqueous solution.

The decomposition of PET $(0.5 \mathrm{~g}, 2.6 \mathrm{mmol})$ in non-aqueous DMI $(30 \mathrm{ml})$ with $\mathrm{NaOH}(0.41 \mathrm{~g}, 10.2$ mmol, $2.0 \mathrm{~mol}$ equivalent to PET) at $120-150^{\circ} \mathrm{C}$ was carried out for comparison with alcohols except that ethereal additives were not used, and TPA-Na $\mathrm{Na}_{2}$ was obtained after removal of DMI by distillation and acidification of the residue.

\section{RESULTS AND DISCUSSION}

\section{Choice of Alcohols}

The rates of alkali-decomposition of PET pellets

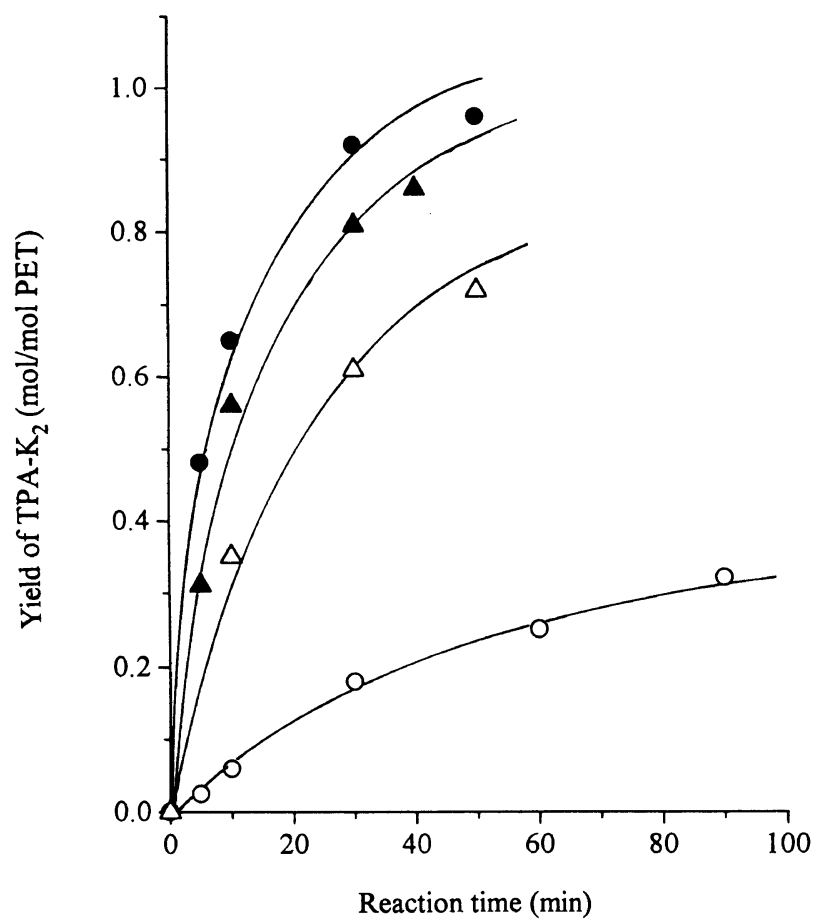

Figure 2. Formation of TPA-K $\mathrm{K}_{2} v s$. time of decomposition with $\mathrm{KOH}\left(2 \mathrm{moll}^{-1}\right)$ at $50^{\circ} \mathrm{C}$ in a mixed solvent of ethanol and ethers $(80 / 20$ vol\%): no ether $(\bigcirc)$, dioxane $(\mathbf{O})$, tetrahydrofuran $(\boldsymbol{\Delta})$, and 1,2-dimethoxyethane $(\triangle)$

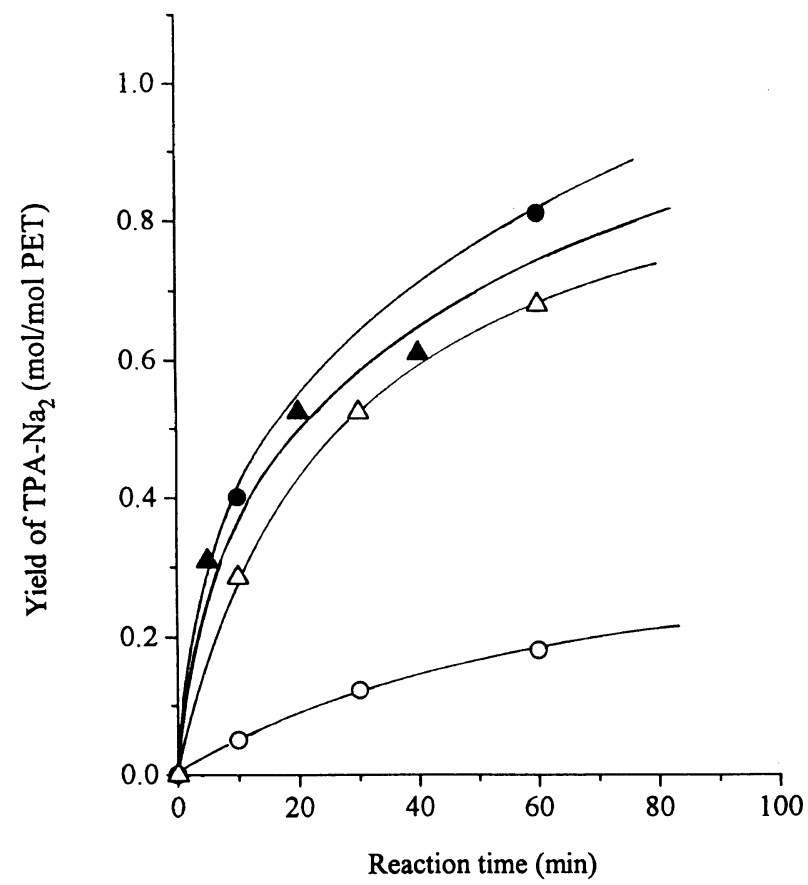

Figure 3. Formation of TPA-Na ${ }_{2} v s$. time of decomposition with $\mathrm{NaOH}\left(2 \mathrm{moll}^{-1}\right)$ at $50^{\circ} \mathrm{C}$ in a mixed solvent of methanol and ethers $(80 / 20$ vol\%): no ether $(\bigcirc)$, dioxane $(\mathbf{O})$, tetrahydrofuran $(\boldsymbol{\Delta})$, and 1,2-dimethoxyethane $(\triangle)$.

(Type-1) with $\mathrm{KOH}$ in three alcohols, i.e., $\mathrm{MeOH}$, EtOH, and 1-propanol were measured at $60^{\circ} \mathrm{C}$ and shown in Figure 1, expressed as weight of unreacted pellets. $\mathrm{EtOH}$ and $\mathrm{MeOH}$ seem to be good combination with $\mathrm{KOH}$ and, therefore, were used in the following experiments.

Effect of Ethereal Additives on the Rate of Decomposition To accelerate the rate of decomposition, an ethereal 
Table I. Time for complete decomposition of PET with $\mathrm{NaOH}$ in mixed solvent of ether/methanol $(0.5 / 4.5 \mathrm{ml})$ at $60^{\circ} \mathrm{C}$

\begin{tabular}{|c|c|c|c|c|c|c|}
\hline \multirow{2}{*}{ Ethers } & \multicolumn{2}{|c|}{$\mathrm{PET} / \mathrm{g}$} & \multirow{2}{*}{$\frac{\mathrm{NaOH}}{\mathrm{g}}$} & \multirow{2}{*}{$\frac{\text { Reaction time }}{\min }$} & \multirow{2}{*}{$\frac{\text { Yield (TPA) }}{\text { mol } \%}$} & \multirow{2}{*}{$\begin{array}{c}\text { Unreacted remaining PET } \\
\text { mol } \%\end{array}$} \\
\hline & Pellets & Bottle flakes & & & & \\
\hline Dioxane & 0.50 & - & 0.41 & 40 & 97 & 2.9 \\
\hline Tetrahydrofuran & $\begin{array}{c}0.50 \\
-\end{array}$ & $\overline{0.50}$ & $\begin{array}{l}0.41 \\
0.41\end{array}$ & $\begin{array}{r}60 \\
150\end{array}$ & $\begin{array}{l}98 \\
99\end{array}$ & $\begin{array}{l}1.7 \\
0.3\end{array}$ \\
\hline Dimethoxyethane & 0.49 & - & 0.41 & 105 & 98 & 1.5 \\
\hline None & $\begin{array}{c}0.50 \\
-\end{array}$ & $\overline{0.50}$ & $\begin{array}{l}0.41 \\
0.42\end{array}$ & $\begin{array}{l}300 \\
420\end{array}$ & $\begin{array}{l}96 \\
96\end{array}$ & $\begin{array}{l}2.1 \\
3.0\end{array}$ \\
\hline
\end{tabular}

Table II. Time for complete decomposition of PET in EG $(5 \mathrm{ml})$ with $\mathrm{NaOH}(0.42 \mathrm{~g})$ at $180^{\circ} \mathrm{C}$

\begin{tabular}{cccccc}
\hline \multicolumn{2}{c}{ PET/g } & \multicolumn{2}{c}{$\begin{array}{c}\text { Reaction time } \\
\text { Y Yield of TPA }\end{array}$} & $\begin{array}{c}\text { Remaining } \\
\text { of PET }\end{array}$ \\
\cline { 1 - 1 } Pellets & Bottle flakes & min & mol \% & mol \% \\
\hline 0.5 & - & 3 & 97.0 & 2.0 \\
0.96 & - & 15 & 99.0 & 0.3 \\
- & 0.5 & 3 & 95.5 & 3.8 \\
- & 0.5 & 5 & 99.3 & 0.0 \\
- & 0.5 & 7 & 99.5 & 0.0 \\
- & 0.5 & 10 & 99.5 & 0.0 \\
- & 0.96 & 15 & 99.6 & 0.0 \\
\hline
\end{tabular}

additive, dioxane (DX), tetrahydrofuran (THF), or 1,2-dimethoxyethane (DME), was added to $\mathrm{MeOH}$ or EtOH (ether $20 /$ alcohol $80 \mathrm{vol} \%$ ) and the rates were measured at $50^{\circ} \mathrm{C}$ in terms of yield of TPA-K $\mathrm{K}_{2}$ or $-\mathrm{Na}_{2}$ as shown in Figures 2 and 3. Two significant features are shown in the Figures: (1) $\mathrm{KOH}$ is more effective than $\mathrm{NaOH}$; (2) addition of an ethereal additive accelerates the rate of decomposition several times than in pure alcohol, regardless of the alcohol or alkali metal hydroxide. For example, the yield of TPA- $\mathrm{K}_{2}$ after treatment in pure $\mathrm{EtOH}$ for $30 \mathrm{~min}$ at $50^{\circ} \mathrm{C}$ was only $18 \%$, but increased to $60 \%$ by the addition of $20 \%$ DME, $82 \%$ by THF, and $92 \%$ by DX.

Appropriate combinations of alkali hydroxide and alcohol for effective decomposition are shown in Figure 4. With $\mathrm{KOH}, \mathrm{EtOH}$ seems better whereas with $\mathrm{NaOH}$ it is $\mathrm{MeOH}$. Therefore, in the following experiments we used these combinations.

Table I shows the time required for the complete decomposition (depolymerization) of PET pellets $(0.50 \mathrm{~g})$ at $60^{\circ} \mathrm{C}$ with $\mathrm{NaOH}(0.41 \mathrm{~g})$ dissolved in a mixed solvent of $\mathrm{MeOH}(4.5 \mathrm{ml})$ and $10 \mathrm{vol} \%$ of an ethereal additive $(0.5 \mathrm{ml})$. In comparison with the time $(300 \mathrm{~min})$ required in pure $\mathrm{MeOH}$, addition of DME, THF, or DX to the alcohol clearly shortened the time to 105,60 , or $40 \mathrm{~min}$, respectively. Instead of the pellets, when cut pieces of PET-bottles were subjected to the conditions at $60^{\circ} \mathrm{C}$, somewhat longer reaction times were required for complete decomposition probably due to higher degree of crystallinity. In contrast, the same cut pieces in much higher boiling alcohol EG at $180^{\circ} \mathrm{C}$ underwent decomposition at a comparable rate or even faster than the pellets at the same temperature (see Table II).

In all cases, ethers clearly accelerated the rate of decomposition in the order, DME $<$ THF $<$ DX. For example, based on kinetic analysis, the first-order rate

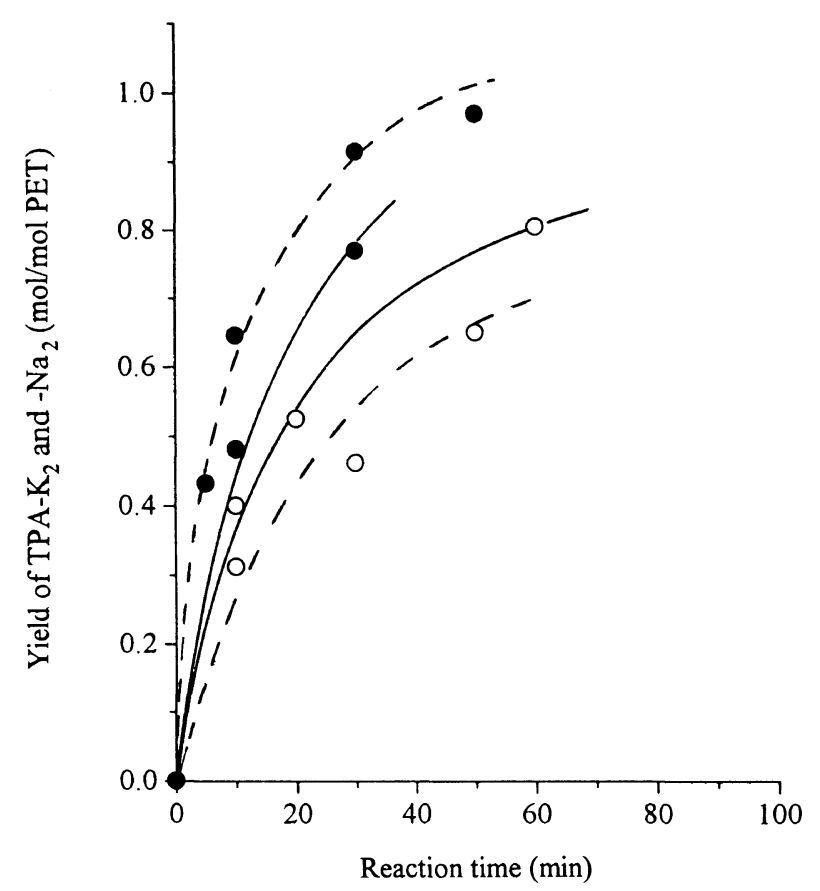

Figure 4. Comparison of alcohol in the decomposition of PET with $\mathrm{KOH}$ or $\mathrm{NaOH}$ in a mixed solvent of alcohol and dioxane $(80 / 20$ vol\%) at $50^{\circ} \mathrm{C}: \mathrm{NaOH}(\mathrm{O}), \mathrm{KOH}(\bullet)$, in ethanol-dioxane (-----), and methanol-dioxane $(\stackrel{\longrightarrow}{\longrightarrow}$.

constants $^{27}$ of the decomposition with $\mathrm{KOH}$ in $\mathrm{EtOH}$ at $50^{\circ} \mathrm{C}$ were calculated on the basis of Figure 2 to be $0.0065 \mathrm{~min}^{-1}$ in pure EtOH, 0.1314 with $20 \% \mathrm{DX}$ in EtOH, 0.0736 with $20 \%$ THF, and 0.0430 with $20 \%$ DME. This may be due to: (1) elongation of the surface matrix of solid PET by the ethereal solvent accelerating the percolation of hydroxide ion, and (2) chelation effect of an ethereal solvent with an alkali cation to increase the ion strength of hydroxide ion. Decomposition may take place on the surface of the PET solids, not in solution and, therefore, decrease in molar quantity of PET solids must be equivalent to the increase in disodium terephthalate.

After examining the rate-acceleration effect of ethers at a constant mixing ratio, e.g., $20 \mathrm{vol} \%$ for Figures 2 and $3,10 \%$ for Table I, we investigated the proper mixing ratio of ethers in alcohols at $50^{\circ} \mathrm{C}$. The results are shown in Figure 5. With $\mathrm{KOH}$ in $\mathrm{EtOH}$, the yield of TPA- $\mathrm{K}_{2}$ reached maximum when $40-50 \mathrm{vol} \%$ of DX or THF was added and decreased beyond this point. With $\mathrm{NaOH}$ in $\mathrm{MeOH}$, the yield of TPA- $\mathrm{Na}_{2}$ straightly increased as the amount of DX was increased up to $60 \mathrm{vol} \%$ where precipitation of $\mathrm{NaOH}$ began. In view 


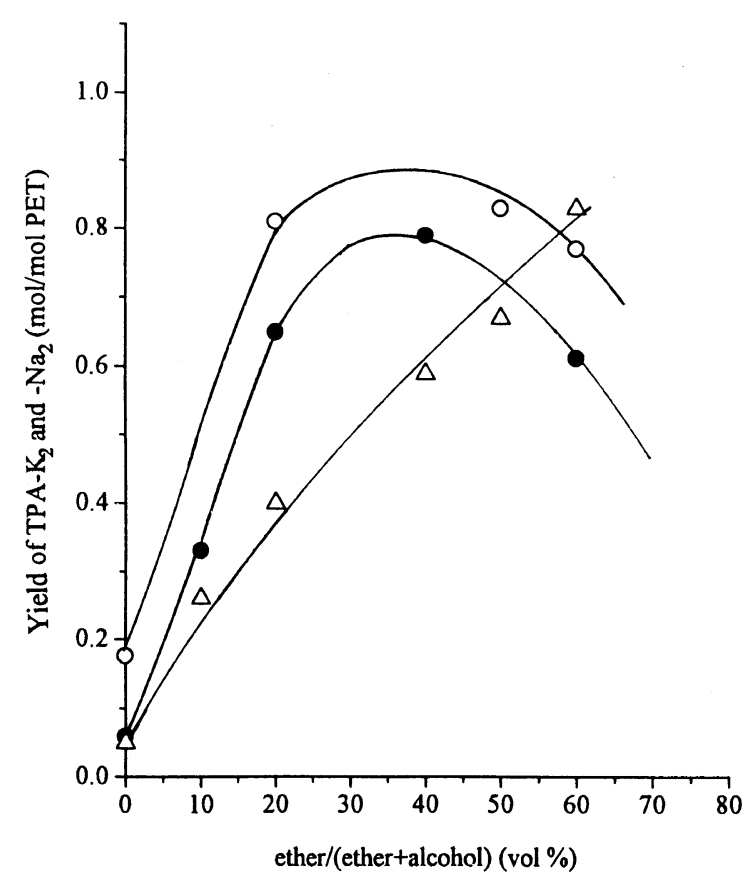

Figure 5. Effects of ether concentration on the formation of TPA-K in a mixed solvents at $50^{\circ} \mathrm{C}$ : dioxane in ethanol for $10 \mathrm{~min}(\mathrm{O})$, tetrahydrofuran in ethanol for $30 \mathrm{~min}(\mathrm{O})$, formation of TPA- $\mathrm{Na}_{2}$ : dioxane in methanol for $10 \mathrm{~min}(\triangle)$.

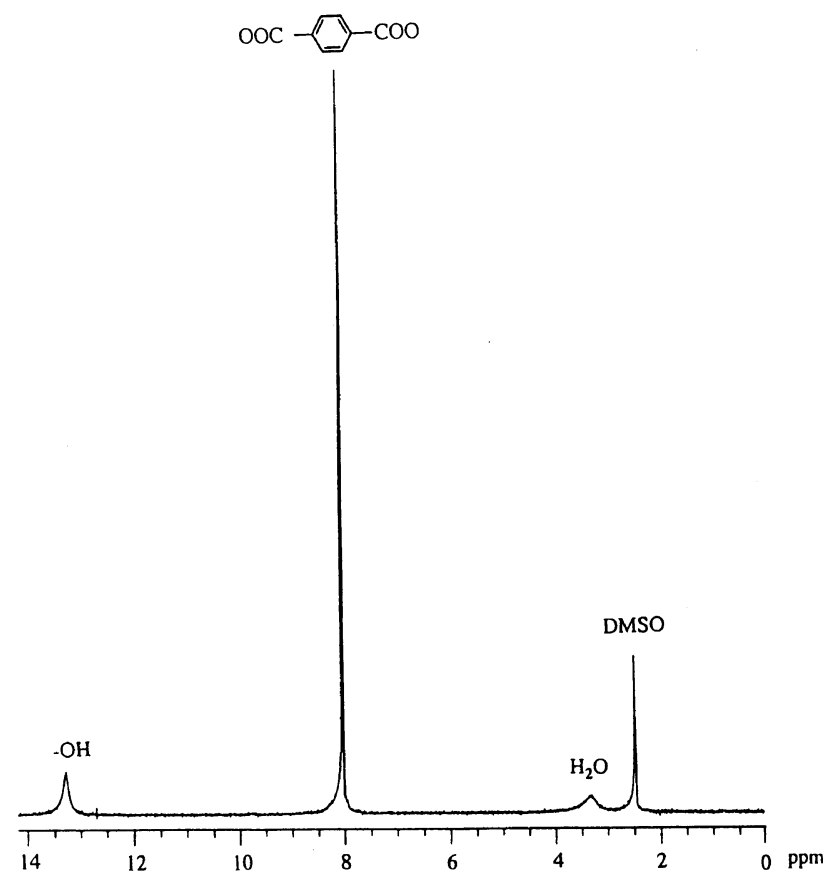

Figure 6. ${ }^{1} \mathrm{H}$ NMR spectrum of TPA obtained from the decomposition of PET bottle flakes for $150 \mathrm{~min}$ at $60^{\circ} \mathrm{C}$ in a mixed solvent of methanol and tetrahydrofuran $(80 / 20 \mathrm{vol} \%)$.

of practical application to industrial purposes, we adopted $10-20 \%$ concentrations of ethers for most experiments in the present study.

\section{${ }^{1} H$ NMR Analysis}

Figure 6 shows the ${ }^{1} \mathrm{H}$ NMR spectrum of TPA obtained after the decomposition of PET bottle flakes with $\mathrm{NaOH}$ in $\mathrm{THF}-\mathrm{MeOH}$ followed by precipitation with $\mathrm{HCl}$. Within the detection limit of the spectroscopy, no ethylene residue of EG appeared.

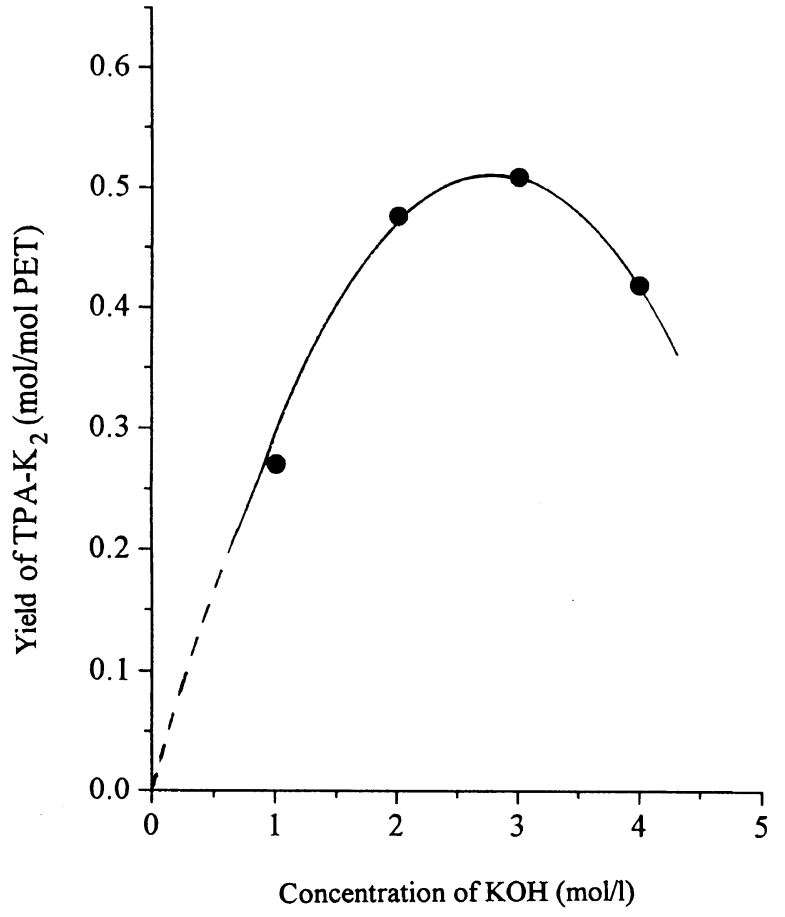

Figure 7. Effects of $\mathrm{KOH}$ concentrations on the formation of TPA-K 2 in ethanol after the treatment of $30 \mathrm{~min}$ at $60^{\circ} \mathrm{C}$. Initial concentration of $[\mathrm{PET}]=1 \mathrm{moll}^{-1}$.

\section{Effect of Alkali Concentration}

Figure 7 shows the effect of $\mathrm{KOH}$ concentration on the decomposition of PET carried out in $\mathrm{EtOH}$ at $60^{\circ} \mathrm{C}$ for $10 \mathrm{~min}$. As concentration increases, the rate of decomposition accelerated but reached a maximum at $2-3 \mathrm{~mol} \mathrm{KOH}^{-1}$. The decrease in rates beyond this critical point may be ascribable, at least partly, to the slower rate of exfoliation of TPA-K $\mathrm{K}_{2}$ from the pellet surface due to increase in solvent viscosity.

\section{Decomposition in DMI without Ethereal Additives}

In comparison with the above decomposition in alcohol-ether systems and also the report by Tindall and Perry in aprotic solvents, ${ }^{21}$ we examined alkali decomposition of PET in DMI without ethers. DMI is an industrially available solvent and reported to be a high-boiling aprotic polar solvent resistant to rigorously acidic and basic conditions. ${ }^{27}$ The decomposition of PET pellets in DMI with $\mathrm{NaOH}$ at $150^{\circ} \mathrm{C}$ proceeded efficiently and, after heating for $1 \mathrm{~h}$, DMI was removed by distillation and the residue was acidified to yield TPA quantitatively $(99 \%)$. The rate was relatively slow at $120^{\circ} \mathrm{C}$ so that TPA was formed in $85 \%$ after $1 \mathrm{~h}$. DMI was recovered without appreciable decomposition under these conditions. Though efficient, we assume that this process may be not so practical as that with alcohol-ether systems due to the high boiling point of DMI $\left(225^{\circ} \mathrm{C}\right)$.

\section{CONCLUSIONS}

In comparison with the preceding study on the alkalidecomposition of PET in EG, ${ }^{19}$ the characteristics of the present method are summarized as follows: (1) in place of EG, methanol and ethanol can be used in combination with ethereal additives such as dioxane and tetrahydrofuran; (2) in the present combined solvent 
systems, applicable decomposition temperatures are $60-80^{\circ} \mathrm{C}$, which in general are much lower than those $\left(150-180^{\circ} \mathrm{C}\right)$ in the single use of EG; (3) salts of TPA are separated quantitatively as powdery precipitates while the liquid filtrate (mainly EG) is recycled repeatedly and increased volume of the filtrate is distilled for the recovery of EG; (4) both TPA and EG can be obtained nearly quantitatively.

For solving the social problems caused by plastic wastes, the present study may make possible, to some degree, the chemical recycling of waste PET.

\section{REFERENCES AND NOTES}

1. S. F. Pusztaszeri, U. S. Patent 43551751 (1982)

2. T. Yoshida, T. Sato, and A. Okuwaki, J. Appl. Polym. Sci., 52, 1353 (1994).

3. T. Yoshioka, Y. Kamiya, T. Sato, and A. Okuwaki, Proceedings, 1st International Conference on Solvo-Thermal Reaction, 1994, p 76 .

4. U. R. Vaidya and V. M. Nadkarni, J. Appl. Polym. Sci., 38, 1179 (1989).

5. S. Baliga and W. T. Wong, J. Polym. Sci., A, 27, 2071 (1989).

6. U. R. Vaidya and M. Nadkarni, J. Appl. Polym. Sci., 35, 775 (1988).

7. K. Tomita, Polymer, 17, 221 (1976)

8. K. Tomita and H. Ida, Polymer, 16, 186 (1975).

9. K. Tomita and H. Ida, Polymer, 14, 55 (1973).

10. U. R. Vaidya and V. M. Nadkarni, Ind. Eng. Chem. Res., 26, 194 (1987).

11. U. R. Vaidya and V. M. Nadkarni, J. Appl. Polym. Sci., 34, 235 (1987).

12. J. R. Campanelli, M. R. Kamel, and D. G. Cooper, J. Appl. Polym. Sci., 48, 443 (1993).
13. K. S. Sed and D. Cloyd, J. Appl. Polym. Sci., 42, 845 (1991)

14. J. W. Mandoki, U. S. Patent 4605762 (1986).

15. T. Adschiri, R. Malaluan, K. Machida, O. Sato, and K. Arai, Proceedings, 1st International Conference Solvo-Thermal Reaction, 1994, p 138

16. Y. Kuroda, R. Yamaguchi, and R. Matsumoto, Patent, Japan Kokai 48-68538 (1973).

17. J. R. Campanelli, M. R. Kamel, and D. G. Cooper, J. Appl. Polym. Sci., 54, 1731 (1994).

18. J. Y. Chen, C. F. Ou, Y. C. Hu, and C. C. Lin, J. Appl. Polym. Sci., 42, 1501 (1991).

19. A. Oku, L-C. Hu, and E. Yamada, J. Appl. Polym. Sci., 63, 595 (1997).

20. $\mathrm{NaCl}$ can be recycled in the form of $\mathrm{NaOH}$, and $\mathrm{Na}_{2} \mathrm{SO}_{4}$ can be used in large scales on a wide commercial basis.

21. G. W. Tindall and R. L. Perry, PCT Int. Appl. WO 9109,004 (1991); Japan Kokai 8-502964 (1996).

22. DMSO, DMF and NMP are not so stable in strong alkaline solutions. For example, $70 \%$ of NMP is decomposed by the treatment with $10 \%$ aq $\mathrm{NaOH}$ at $100^{\circ} \mathrm{C}$ for $12 \mathrm{~h}$ and $14 \%$ with $10 \% \mathrm{~K}_{2} \mathrm{CO}_{3}$ at $200^{\circ} \mathrm{C}$ for $12 \mathrm{~h}$.

23. W. P. Weber and W. Gokel, "Phase Transfer Catalysts in Organic Synthesis," Springer KG, Berlin, 1977.

24. The reaction system is composed of liquid-solid bi-phases. The depolymerization takes place rapidly on the solid surface before dissolution of the polymer.

25. Two types of PET pellets, $M_{\mathrm{w}}=30000$ and 33000 , behaved similarly under the conditions examined.

26. Chemical stability of DMI in acids and alkalis is reported much higher than that of DMSO, DMF, and NMP. M. Fieser, "Fieser and Fieser's Reagents for Organic Synthesis," Vol. 11, John Wiley \& Sons, New York, N.Y., 1984, p 202.

27. In the kinetic treatment of this solid-to-liquid depolymerization, the concentration of PET must be constant because the surface of PET pellets can be considered equivalent to the PET concentration; see also ref 19. 